\title{
EMPECILHOS AO TRATAMENTO ISONÔMICO LGBTI: ANÁLISE DO PRECONCEITO EM SUA FORMAÇÃO CULTURAL E LEGISLATIVA
}

Resumo: Ainda que os últimos anos tenham sido de relevantes avanços para a população LGBTI (lésbicas, gays, bissexuais, trans e intersexuais) na questão de isonomia social, observa-se que a efetivação de alguns direitos já garantidos ainda é dificultada pelo poder público, assim como outros direitos continuam sendo omitidos das pautas dos legisladores, criando obstáculos para as oportunidades dessa população nos mais variados segmentos da sociedade em razão de um preconceito enraizado. Este artigo busca elencar as causas dessa desigualdade, bem como entender até que ponto a cultura, influenciada pelo direito canônico, impede a outorga desses direitos e a quebra da heteronormatividade.

Palavras-Chave: LGBTI; isonomia; preconceito.

Abstract: Although the recent years have been of significant advances for the LGBTI population (lesbian, gay, bisexual, trans and intersexual) amongst the social isonomy issue, it is observed that the accomplishment of some already guaranteed legal rights is still hampered by the public power, as well as other rights that continue to be omitted on the legislative agenda, creating obstacles to the opportunities of this specific population in the most varied segments of society, due to a deeprooted prejudice. This paper aims to list the causes of this inequality and also to understand to what extent culture, influenced by canon law, prevents the granting of these rights and the breakdown of heteronormativity.

Keywords: LGBTI; isonomy; prejudice.

\section{Introdução}

Em um país com dimensões continentais e uma ampla diversidade cultural, a pluralidade deveria ser encarada como algo comum. A Declaração Universal sobre a Diversidade Cultural [UNESCO] ainda destaca a pluralidade de culturas como algo intrínseco e necessário como a multiplicidade biológica para a natureza de forma que, como

\footnotetext{
${ }^{1}$ Centro Universitário da Fundação Assis Gurgacz
} 
expressa a própria Constituição Federal, a igualdade e a dignidade sexual sejam garantidas com respeito a todas diferenças, sejam elas de origem, raça, sexo, cor, idade.

Contudo, apesar dos grandes avanços de forma a romper gradualmente com essa desigualdade, uma parte de nossa população ainda parece ser ignorada pelas políticas públicas: o grupo LGBTI. Devido a uma cultura amplamente influenciada pela heteronormatividade e a relação de hierarquização sexual que dessa decorre, a liberdade sexual e a identidade de gênero ainda são preconceitos enraizados em nossa sociedade.

Esse trabalho busca resgatar os motivos desse preconceito e compreender a forma como ele afeta o desenvolvimento de nosso país bem como o próprio desenvolvimento pessoal do indivíduo na sociedade, que muitas vezes passa a negar sua identidade para não ser excluído do ambiente em que está inserido. $\mathrm{O}$ sexismo é uma prática histórica que, mesmo que seja sabido não ser natural, é implícita no nosso cotidiano, sendo fundamento do desprezo pelo sexo feminino e, consequentemente, da homossexualidade, e muito reforçada pelo direito canônico ao passar dos anos. Dessa forma, a análise da relação entre Igreja e Estado é um dos principais pontos a serem analisados; embora sejam hoje conceitos separados, em tese, em nosso ordenamento jurídico, nossa cultura ainda guarda traços preconceituosos em relação a identidade de gênero, sendo motivo de violência física e psicológica, evasão escolar e a transformação do mercado de trabalho em um ambiente hostil, assim como outros problemas sociais.

Ainda, o exposto artigo contribui para o entendimento quanto a influência da cultura da sociedade para o entrave dos avanços na garantia dos direitos dessa população, discutindo a inércia legislativa e mudança ideológica na cultura social. Sabe-se que um grande empecilho na garantia da igualdade dessa população é a atual falta de legislação que criminalize a homofobia, sendo a única forma de discriminação a não possuir proteção própria em nosso ordenamento jurídico e não garantindo a segurança necessária a esses indivíduos.

\section{A evolução da sexualidade humana através do tempo}

Um ordenamento jurídico nada mais é do que a normatização e hierarquização das condutas humanas e dos direitos sociais mais importantes em um determinado momento para a sociedade a que lhe serve, como explica John Rawls (1997). Ainda de acordo com o autor, a constituição deve ser estruturada de modo que seja o instrumento com maiores probabilidades de resultar num sistema de legislação justo e eficaz.. Dessa forma, por ser 
baseada em uma maioria, muitos tabus e preconceitos enraizados em nossa cultura são explicados através de uma análise da formação desse sistema jurídico, que desde sua criação foi fundamentado no padrão de um sujeito branco, cristão e heterossexual.

À vista disso, é compreensível como o conceito da sexualidade no berço da sociedade é capaz de moldá-la. A ideia do pátrio poder familiar advém justamente do sexismo resultante do desenvolvimento natural da espécie; a mulher era vista como um homem incompleto e subordinada ao seu companheiro, e seus papeis sociais eram previamente estabelecidos por essa submissão, em que ao homem é devida a vida exterior e política, enquanto o papel da mulher repousa na intimidade e nas atividades doméstica (BORRILLO, 2015). Ademais, a dependência do sexo feminino ao masculino era estendida à intimidade do casal: na Grécia Antiga, por exemplo, o sexo entre o homem e a mulher só era admitido com o objetivo de procriação, enquanto o ato sexual como fonte de prazer tinha aceitação quando praticado entre homens, sendo, portanto, a libido aprovada apenas para o sexo masculino.

Levando-se em consideração a sexualidade como uma relação de poder, de forma bem explanada por Michel Foucault desde o século $\mathrm{XX}$, a sexualidade humana fundamentou-se na ideia de sexo forte versus sexo frágil, valorizando a virilidade que, segundo BORRILLO (2015), fundamenta-se na negação da feminilidade e rejeição da homoafetividade (o que explica a inferiorização do sexo feminino e a aversão ao homossexual).

O descaso com as minorias é complementariamente explicado pela influência religiosa na formação social. Decorrente da sacralização da família, a dualidade normal versus anormal é reforçada com a associação do casamento como formador da sociedade (BERENICE, 2014), estabelecendo a heterossexualidade como padrão e condenando como pecado todas variantes de gênero.

Diante do tabu desenvolvido acerca do sexo na sociedade, a maneira como a sexualidade é exposta e a importância desta para o indivíduo foi mitigada através do tempo, de forma que esse conhecimento não conseguiu ser desenvolvido devido a preconceitos sociais e religiosos e pela ignorância resultante do desconhecimento do assunto; precisa-se entendê-la como formadora da identidade pessoal de cada um, de forma que a saúde sexual deveria ser considerada como um direito básico do mesmo modo que a saúde no seu sentido mais amplo (OMS, 1975). Com os movimentos feministas desencadeados na década de 1960 e o declínio da influência cristã no Estado, a concepção de culpa no prazer sexual perdeu força e possibilitou uma liberdade sexual feminina e o 
florescimento da homossexualidade. Associada a influências como o surgimento da contracepção, a independência da mulher foi muito mais do que a possibilidade de limitar a gravidez, possibilitando uma maleabilidade sexual destas e marcando uma profunda transição da sua vida pessoal e passando a ser encarada como propriedade do indivíduo (GIDDENS, 1993).

\section{Conceituação e diferenciação terminológica}

Como consequência da proximidade entre Igreja e Estado, por muito tempo a homoafetividade foi considerada uma doença pela medicina, julgando-a como um defeito genético e vulgarizando a expressão "homossexualismo", com o sufixo que denota doença. Já tendo sido categorizada na Classificação Internacional de Doenças como transtorno sexual e prevista no Código Internacional de Doenças como transtorno psicológico, a busca da origem da homoafetividade até hoje perdura e provoca debates defendendo-se, de um lado, sua origem como biológica, e de outro como cultural.

Aqueles que defendem a teoria em que os aspectos biológicos são preponderantes para

1 A distinção sexo/gênero sugere uma descontinuidade radical entre corpos sexuados e gêneros culturalmente construídos. Quando o status construído do gênero é teorizado como a formação da sexualidade buscavam características que diferissem a formação do indivíduo heterossexual e do homossexual. Um exemplo disso é o estudo da neurocientista Simon Le-Vay que identificou a diferença do hipotálamo de um homossexual para o de um heterossexual; outro, a pesquisa de Sandra Witelson, que verificou uma diferença na região do cérebro entre pessoas de gêneros diferentes.

Enquanto isso, a outra corrente defende os fatores sociais e culturais como formadores da sexualidade humana, o que permitiu o estudo desta com uma maior fluidez, de forma a desenvolve estudos como a teoria queer. $\mathrm{O}$ vocábulo queer, na sua origem, era utilizado como ofensa aos homossexuais, designando algo estranho. Sustentada por Judith Butler, a teoria queer prevê a desconstrução do binário de gênero homem e mulher, considerando que o indivíduo possui uma sexualidade mais fluída entre esses dois extremos. A teoria desmistifica o entendimento de que o gênero depende do sexo atribuído fisicamente à pessoa, conferindo significados diferentes e enriquecendo o debate acerca da sexualidade humana nas sociedades, além de desmistificar os papéis de gênero da heteronormatividade ${ }^{2}$.

radicalmente independente do sexo, o próprio gênero se torna um artifício flutuante, com a consequência de que homem e masculino podem, com igual facilidade, significar tanto um corpo 
Atualmente, apesar da consciência de que a categorização excessiva do ser humano tende a produzir o efeito contrário e separá-lo, de forma a contribuir com o preconceito e uma esteriotipização desnecessária, faz-se mister distinguir alguns conceitos no campo da sexualidade humana e reafirmá-los para garantir a devida igualdade a essas minorias. Primeiramente, o gênero não deve ser confundido com sexo: o primeiro é compreendido como um conceito culturalmente construído e pode estar dissociado do sexo, que é aquele predeterminado por nossas genitálias no nascimento. É diante dessa constatação que Simone Beauvoir expressa que "Não nascemos mulher, tornamo-nos mulher".

Diante disso, uma primeira diferenciação importante para a compreensão da amplitude do gênero é entre a população transgênero e a cisgênero. Entende-se como cisgênero (do latim, cis significa mesmo lado) a pessoa que se identifica com seu sexo biológico, enquanto o transgênero, de forma contrária, não se identifica com seu sexo, total ou parcialmente. O significado do termo transgênero ainda é muito discutido em nosso país e gera divergência entre os especialistas, de forma que, atualmente, utiliza-se "trans"

feminino como um masculino, e mulher e feminino, tanto um corpo masculino como um feminino. (BUTLER, 2015, p. 26) como uma expressão guarda-chuva, abarcando os trangêneros, travestis e transexuais, sendo aprovada a utilização do termo "trans" ou a letra "T" no Congenid (Congresso Internacional sobre Identidad de Género y Derechos Humanos). Contudo, para a maior parte dos estudiosos, a expressão transexual designa os indivíduos que sentem desconexão psíquico-emocional com o seu sexo biológico. Diferente destes são os travestis, termo usado para as pessoas que não necessariamente identificam-se com outro gênero do biológico, mas que incorporam os papéis de gênero diverso.

Os papéis de gênero são conceitos originados por uma visão heterossexual, tendo em vista os traços de enaltecimento de características masculinas e a inferiorização dos traços femininos, que abarcam mulheres e dos homossexuais. Essa subvalorização é compreendida visto que abrange, na sua variante passiva, muito mais do que o ato sexual de ser penetrado: a submissão destes indivíduos pelos conceitos de feminilidade. Apesar da luta dessas minorias em busca da quebra da heteronormatividade e a consequente equiparação dos papeis de gênero, muitas vezes eles são reforçados por esses mesmos indivíduos na sua forma de vestir-se e 
comportar-se, consequência de um machismo enraizado difícil de libertar.

A orientação sexual, todavia, pode ser definida como um impulso sexual de cada indivíduo, a forma como este canaliza sua sexualidade (DIAS, 2014). Atualmente, optase pelo termo orientação sexual no lugar da expressão opção sexual, pois se entende que o desejo sexual não é uma escolha. Com relação à orientação sexual, destacam-se os termos heterossexual, homossexual e bissexual. Heterossexual, como conceitua o dicionário Aurélio (2016), refere-se àquele "que sente atração ou interesse sexual pelo sexo oposto." De forma contrária, o termo homossexual designa o indivíduo que sente atração emocional, sexual ou afetiva por pessoas do mesmo sexo, abarcando a comunidade lésbica (feminina) e gay (masculina). Destaca-se, neste ponto, a evolução do termo "homossexual", que passou do tratamento como doença, com o sufixo ismo, à denominação mais moderna por Maria Berenice Dias de "homoafetividade". O emprego do sufixo "dade", que significa modo de ser, destaca o afeto como característica da união entre pessoas do mesmo sexo, afastando a ideia de puro prazer sexual destes. Por último, compreende-se como bissexual a pessoa que sente atração por pessoas de ambos os sexos, sendo uma comunidade que ainda sofre grande preconceito.
Enquanto a orientação sexual expressa a forma como o indivíduo reconhece $o$ próximo, Maria Berenice (2014) conceitua identidade de gênero como a forma pela qual a pessoa se reconhece. A autora frisa, ainda, que esta independe dos órgãos genitais e de qualquer característica anatômica, uma vez que a anatomia não define o gênero.

Por fim, temos a expressão intersexo, que teve sua inicial adicionada recentemente, por alguns autores, na sigla LGBT, transformando-a em LGBTI. O termo intersexo representa a antiga expressão "hermafrodita”, e está ligada a traços genéticos da pessoa, como uma diferenciação dos seus órgãos reprodutivos.

\section{As influências sociais na compreensão do gênero na sociedade}

Desde o início da discussão sobre a sexualidade no meio social, essa deixou de ser um assunto pessoal do indivíduo, representada apenas pela busca do prazer, para ser objeto de estudo conjunto dos mais variados setores da sociedade, passando pela biologia, sociologia e inserindo-se, inclusive, no campo econômico da mesma (FOUCAULT, 1984).

No que tange a compreensão de gênero e sexualidade, vemos duas grandes influências ao longo do tempo: de um lado a religião, que muito colaborou para a construção dos primeiros dogmas do Estado, mais 
conservadores; de outro, o movimento feminista buscou uma rediscussão destes dogmas, bem como um debate sobre igualdade de direitos e liberdade de gênero.

Sendo Portugal a nação mais católica e conservadora das nações da Europa (GOMES, 2007), a influência da religião foi muito intensa no processo de colonização do Brasil, o que é claramente visível com a outorga da primeira constituição brasileira, em 1824, que instituía o catolicismo como religião oficial do país. Essa determinação culminou em uma relação muito próxima entre Igreja e Estado, tornando-se, em alguns momentos, conceitos indistintos.

Apesar da separação entre Igreja e Estado posterior, com a primeira constituição republicana, os traços do catolicismo ainda são enraizados na cultura e, também, no próprio direito. Na vigente Constituição de 1988, a influência da religião é nítida na edição de seu preâmbulo com os dizeres "sob a proteção de Deus", de modo que muitos autores questionam a necessidade desta redação frente ao Estado Laico. O Supremo Tribunal Federal, entretanto, já se manifestou sobre o assunto, justificando que o preâmbulo constitucional não possui valor normativo, de forma que a referência à Deus possui apenas caráter político-ideológico, não se situando no domínio do direito.

Por a crença religiosa ser ainda arraigada nos costumes e nos conceitos de ética na sociedade moderna, a proliferação de discursos de ódio e violência contra o segmento LGBTI, como destacado no relatório final da $3^{\mathrm{a}}$ Conferência Nacional LGBTI em 2016, tem sido um dos grandes desafios da causa. Ainda, em virtude da influência religiosa na cultura de nosso país, a religião acaba por interferir em decisões sociais como a legalização do aborto, a doação de órgãos, pesquisa com células-tronco e o casamento homossexual (FAVORETO, 2016).

Um dos motivos para ser colocada em pauta a real laicidade do Estado brasileiro é a existência de uma bancada religiosa em nosso legislativo, sendo a terceira maior do Congresso. A discussão surge pelo motivo pelo qual a bancada é mais reconhecida nos meios midiáticos: a discussão de direitos individuais em projetos de acordo com suas convicções religiosas. Dessa forma, as decisões da bancada, baseadas em suas crenças particulares, ofendem o seu eleitorado, as minorias sociais e, consequentemente, a laicidade do Estado.

Como explica FOUCAULT (1984), a ignorância sobre a sexualidade, causada pelo preconceito histórico do assunto bem como a demora da sua discussão nas camadas sociais mais baixas, é perigosa e teve grande importância na falta de conhecimento da sexualidade humana até hoje, o que explica a heteronormatividade, o machismo e a homofobia enraizada na sociedade. 
Em contraponto, na compreensão e abordagem dos movimentos LGBTIs ao longo da história em busca de seus direitos, destacase como as ondas feministas em nosso país, como são conhecidos os primeiros movimentos feministas, os quais tiveram grande influência para o enfraquecimento do patriarcado e contribuiram para uma rediscussão acerca do machismo na sociedade, em prol de uma sociedade sem hierarquia de gêneros. Do direito ao voto até o lançamento da pílula anticoncepcional, as mulheres colocaram em pauta a relação de poder do homem sobre a mulher (PINTO, 2010).

A reinterpretação do significado de gênero, exaustivamente discutido por Simone de Beauvoir, foi essencial para o surgimento das reivindicações das mulheres e, posteriormente, embasar as lutas LGBTI. Ao dizer que "não se nasce mulher, torna-se" a autora propõe a ideia de que o sexo biológico não pressupõe o gênero o que, além de incluir mulheres trans na luta contra a opressão histórica, esclarece como os papéis de homens e mulheres foram impostos na sociedade (RIBEIRO, 2014).

\section{O tratamento LGBTI atual no ordenamento} jurídico brasileiro e as questões que ainda precisam ser enfrentadas

Não obstante a heteronormatividade presente em nossa cultura dificulte essa visão, sabe-se que a existência do grupo LGBTI é uma verdade histórica, e não uma criação moderna. Apesar disso, a falta de iniciativa do legislador para incluir essa população no texto legal acaba por obstar a igualdade na concessão de direitos a eles e a falta de reconhecimento destes como cidadãos. Em conformidade com BEAUVOIR (1970, p.19), "quando um indivíduo ou um grupo de indivíduos é mantido numa situação de inferioridade, ele é de fato inferior."

Apesar do preconceito enraizado e da dificuldade na visão do gênero como algo que, assim como teve seus papéis criados ao longo da história pode ter os mesmos desconstruídos, o país conseguiu obter alguns avanços nos últimos anos, principalmente com a promulgação da Constituição Federal de 1988 que abriu precedentes para um tratamento mais isonômico.

A partir de uma constituição mais democrática e inclusiva, o país pode obter avanços no campo cível, a começar pela definição de família. Curiosamente, o Código Civil de 2002 e a Constituição Federal de 1988 não conceituaram família no seu texto legal, dando-o a entender como sinônimo de matrimônio. Foi a Lei Maria da Penha de 2006 que, apesar de ter como objetivo a proteção da mulher (direito extensível a lésbicas, transexuais e travestis), quebrou a omissão legislativa e definiu família como qualquer relação íntima de afeto, ampliando o conceito 
de família de forma a alcançar e dar o primeiro passo ao reconhecimento das uniões homoafetivas.

Os anos seguintes foram de muitos avanços no reconhecimento e destaque do tema da igualdade de gênero no país. A realização da I Conferência Nacional LGBT (2008), a instalação do Conselho Nacional de Combate a Discriminação e Promoção dos Direitos de LGBT (2010), a Criação da Comissão Especial da Diversidade Sexual, com a posterior entrega do Anteprojeto do Estatuto da Diversidade Sexual (2011) são algumas das evoluções das últimas décadas para difundir a discussão do assunto.

Ainda em 2011, o julgamento da Ação Direta de Inconstitucionalidade, ADI 4277 e Arguição de descumprimento de preceito fundamental ADPF 132 resultaram em uma grande quebra de paradigmas e avanço no Direito de Famílias. A dificuldade para o reconhecimento da união homoafetiva como família deu-se principalmente por influência religiosa, diante do argumento de que para constituir-se como família a união devia dar-se por pessoas de sexos diferentes, visto que a união heterossexual é a única sacralizada pelo casamento. O caminho para o reconhecimento da união homoafetiva de forma igualitária à heterossexual passou pela equiparação da união entre casais homossexuais à sociedade de fato e, posteriormente, à união estável. Foi com o julgamento das referidas ações que as uniões homoafetivas foram, finalmente, reconhecidas como entidades familiares. As ações destacaram o fato de não haver referência aos substantivos "homem" e "mulher” na Constituição Federal acerca do casamento, e que a homoafetividade não viola normas jurídicas, tampouco afeta a vida de terceiros.

A Constituição Federal de 1988, também, em seu garantismo, evoluiu ao prever a saúde como direito de todos e dever do Estado, em contraponto ao século passado em que a saúde era direito exclusivo de classes trabalhistas e de cidadãos que pudessem pagar por ela. Além disso, no âmbito da saúde o país tem gradativamente implementado ações para atender à diversidade sexual; a realização de cirurgias de redesignação sexual desde 2008 pelo Sistema Único de Saúde (SUS), terapia hormonal, tireoplastia (cirurgia para a mudança do timbre de voz) são alguns dos progressos para a promoção da dignidade da pessoa humana e a garantia da isonomia nos mais variados segmentos. A Política Nacional de Saúde Integral de lésbicas, gays, bissexuais, travestis e transexuais, elaborada em 2013, é um dos importantes meios do poder público na afirmação da diversidade no âmbito da saúde, ao estabelecer direitos, diretrizes e competências em esfera federal, estadual e municipal.

Mesmo com avanços significativos, o país anda precisa enfrentar questões 
importantes: ainda que a ADI e ADPF supracitadas tenham provocado fortes mudanças para a população LGBTI, é indispensável que essas ações resultem em uma alteração legal. Como esclarece Wyllys (2018), o entendimento do Judiciário pode mudar se a Corte for provocada, e se alterarem membros e contexto de discussão. Segundo o autor, a Corte tem se mostrado muito suscetível à opinião pública ou publicada, às pressões dos jornais, por exemplo.

Ainda, o campo da saúde guarda muita contradição: apesar do grande progresso promovido para a inclusão de tratamentos para transsexuais, exemplos como uma restrição imposta pela ANVISA de 12 meses para "homens que fazem sexo com homens" poderem doar sangue ainda é discutida no STF, além da comunidade LGBTI alegar que faltam campanhas públicas para inserção desta minoria nos tratamentos de saúde bem como preparo dos profissionais, de forma que muitos LGBTIs ainda possuam receio de procurar tratamento e façam com que o índice de doenças sexualmente transmissíveis, por exemplo, sejam muito altos.

Outro ambiente em que encontramos dificuldades de mudanças, além de não haver previsão em lei de forma a assegurar proteção ao grupo LGBTI é o de trabalho; pesquisas acerca da homofobia no mercado de trabalho fortalecem a preocupação: em pesquisa promovida pela Elancers, empresa de sistemas de recrutamento e seleção, em 2015, $18 \%$ das empresas entrevistadas não contrataria um homossexual para alguns cargos. Outro estudo, da consultoria de Santo Caos (2015), afirma que $40 \%$ dos profissionais LGBTs relataram já terem sido vítimas de homofobia dentro do ambiente de trabalho.

No texto do Estatuto da Diversidade Sexual, ainda não aprovado, há a previsão de sistema de costas para travestis e transexuais, com o fim de incentivar a entrada dessa minoria no mercado de trabalho, um dos ambientes onde mais se constata o preconceito com os homoafetivos e, principalmente, transexuais e travestis. As diferenças salariais, demissões de caráter homofóbico e transfóbico bem como as agressões físicas e morais durante o labor são extremamente comuns, e muitas vezes esquecidas diante da falta de meios hábeis a combatê-las e de uma legislação própria que traga segurança a essa população.

\section{Os empecilhos para a concretização dos direitos}

Sabe-se que as normas jurídicas possuem papel fundamental na estipulação do conceito de certo e errado na sociedade, visto que a função destas é refletir os valores sociais de determinada época e garanti-los, conferindo efeitos jurídicos correspondentes (BARROSO, 2002). 
Como previamente observado, as maiores causas da ineficácia de um ordenamento jurídico estão diretamente ligadas a sua formação, o que pode ser observado pelos interesses naturais dos grupos que a redigiram, bem como no idealismo utópico da sua originação. Diante dessas barreiras, o resultado é a atual dificuldade de estender sua interpretação no ritmo do desenvolvimento da sociedade e o persistente controle desses grupos por meio de seus interesses.

A edição de oito constituições (como concorda a maior parte da doutrina) em 100 anos de República reflete, por si só, o cenário de instabilidade das relações jurídicas, políticas e sociais no país; o número de emendas a um texto constitucional em um curto espaço de tempo demonstra, também, um país imaturo juridicamente e a necessidade do sentimento de segurança no ordenamento jurídico ${ }^{3}$. Ainda, como observado por Oliveira Vianna, grande crítico da visão utópica constitucional adotada em nosso ordenamento jurídico brasileiro, a demasiada inspiração doutrinária estrangeira representa uma fuga da realidade de nosso país. Dessa forma, a desconsideração da realidade jurídica, política e econômica do país na formação da sua lei maior, conjuntamente com a crença de que

\footnotetext{
${ }^{3}$ Ao ângulo sociológico, a descontinuidade institucional frustra a cristalização de um sentimento constitucional, resultado último do entranhamento da Lei maior na vivencia diária dos cidadãos, criando uma consciência
}

64

uma constituição deve curar todos os males de uma sociedade, gera um desequilíbrio entre o idealismo e o fatalismo jurídico (BARROSO, 2001).

Por meio da classificação construída por Celso Antônio Bandeira de Melo, pode-se dizer que as normas constitucionais são de três tipos: o primeiro independe de uma prestação alheia, necessitando, apenas, que outrem não embarace o seu desfrute, como o direito à vida; o segundo diz respeito às normas que possuem em seu bojo um desenho de conduta a ser praticado por outrem para garantir sua satisfação completa; o terceiro tipo de norma, porém, constitui-se em uma finalidade a ser cumprida, sem, entretanto, indicar o caminho para atingir esse objetivo, sendo o artigo 226 da Constituição Federal utilizado como exemplo pelo autor, do qual extrai-se que "A família, base da sociedade, tem especial proteção do Estado".

Como o próprio criador da classificação expressa, essas últimas normas não podem ser consideradas irrelevantes por não traçarem um caminho para o Poder Público concretizá-las, mas sabe-se que, com a constante mudança social, cabe à jurisprudência delimitar seus conceitos e alcances, bem como preencher suas lacunas subjetivas, que permitem a sua aplicação de

comunitária de respeito e preservação, como um símbolo superior, de valor afetivo e pragmático (BARROSO, 2001, p. 48). 
formas muito variadas. O artigo $226 \mathrm{da}$ Constituição Federal, anteriormente citado, foi e ainda é palco de grandes discussões doutrinárias e jurisprudenciais; a não inclusão das uniões homoafetivas nesta importante norma constitucional que trata sobre a família, significa, para alguns doutrinadores, um descrédito a união entre pessoas de mesmo sexo e ao princípio da igualdade. Além da omissão da população lésbica e gay nas normas constitucionais, percebe-se claramente uma antinomia jurídica no ordenamento, vez que essa união difere da ideia de casamento trazida no código (CUNHA, 2005).

Portanto, diante de um conflito de normas, atualmente, diferente do que a sociedade exige do direito contemporaneamente, a solução jurídica encontra-se tão somente na interpretação do aplicador do direito, que deverá embasar sua decisão naquela que se aproxime mais da contemporaneidade e da justiça. Infelizmente, opiniões pessoais e valores ainda interferem na vida profissional da maioria dos legisladores, que resistem à inclusão dos LGBTIs no ordenamento jurídico (DIAS, 2014) ${ }^{4}$, além de causar insegurança quanto à concessão de

\footnotetext{
${ }^{4}$ Assim, não há a mínima chance de ser assegura, por lei, aos homossexuais o direito de serem respeitados e de verem seus vínculos afetivos reconhecidos como entidade familiar. Mas ninguém, muito menos um representante do povo, pode se deixar levar pelo discurso religioso, o que afronta a Constituição Federal, a qual assegura a liberdade de credo (CF $5^{\circ}$, VI e 191).A omissão covarde do legislador infraconstitucional em assegurar direito aos homossexuais e reconhecer seus
}

direitos enquanto os entendimentos jurisprudenciais não forem convertidos em lei.

A forte relutância legislativa e o desinteresse em edição de normas e microssistemas que tratem acerca dos direitos da população LGBTI é, ainda, grande problema em nosso país. Projetos como o Estatuto da Diversidade Sexual têm suas discussões adiadas, de forma que a maioria da população, principalmente leiga, não toma conhecimento de sua edição, e o reconhecimento das minorias no âmbito do direito das famílias, previdenciário, trabalhista e sucessório é deixado de lado. A título de exemplo, recentemente o Ministério da Educação modificou o texto da nova versão da base nacional curricular, suprimindo referência à necessidade de respeito à "identidade de gênero" e "orientação sexual". Caso fosse aprovado o Estatuto da Diversidade Sexual, entretanto, os professores e os estabelecimentos de ensino seriam capacitados de modo a coibir formas de discriminação e promover um ambiente mais inclusivo.

A resistência legislativa fortalece-se ainda mais com a falta de representatividade LGBTI no Congresso Nacional, acabando por

relacionamentos, ao invés de sinalizar neutralidade, encobre grande preconceito. O receito de ser rotulado de homossexual, o medo de desagradar seu eleitorado e comprometer sua reeleição inibe a aprovação qualquer norma que assegure direitos à parcela minoritária da população que é alvo da discriminação. 
diminuir ainda mais a voz de uma minoria em nossa sociedade. Sobre a importância da representatividade:

Além de usar a estrutura partidária para, por exemplo, provocar o STF com ADIN [ação direta de inconstitucionalidade], ADPF, que só o partido pode fazer - e o partido só faz se houver a representação lá dentro - o próprio lugar de representação me permite a fala, portanto, instalar o debate. (...) Só o mandato, só a representação permite isso, a instalação do debate, a voz. Eu me levantei e me levanto sempre na tribuna do plenário da Câmara, nas comissões, contra os inimigos dos direitos LGBT e dos direitos humanos em geral. (WYLLYS, 2018).

\section{Considerações Finais}

Este trabalho teve como objetivo tratar dos motivos do preconceito LGBTI e compreender a forma como ele afeta o desenvolvimento de nosso país bem como o próprio desenvolvimento pessoal do indivíduo na sociedade; além de discutir a influência da cultura da sociedade para o entrave dos avanços na garantia dos direitos dessa população, através da inércia legislativa e mudança ideológica na cultura social.

Em virtude dos empecilhos culturais e legislativos abordados neste trabalho para a concessão de direitos ao grupo LGBTI, observa-se que a dificuldade na equiparação de direitos da população heterossexual e homossexual deve-se ao grande tabu heteronormativo em nossa sociedade, de forma a inferiorizar ou, até mesmo, excluir essas pessoas do ambiente social e, consequentemente, das políticas públicas.

Diferentemente do que muitos grupos justificam, a criação de uma legislação para a população LGBTI não viola o princípio da igualdade, e sim o reafirma. Por ser alvo de perseguição e exclusão social pela intolerância ainda presente em nossa sociedade, especialmente da comunidade religiosa, esse grupo merece regras protetivas diferenciadas como todo segmento vulnerável (DIAS, 2014). O Estatuto da Diversidade Sexual, o microssistema que objetiva desde a criminalização da homofobia até a instituição de regras de direito sucessório, possibilita um grande progresso no direito brasileiro por dar validade ao texto já vigente, reafirmando direitos como o a igualdade e dignidade da pessoa humana, e determinar políticas públicas de inclusão dessa população no segmento social, no que se refere à saúde, mercado de trabalho e segurança pública. Infelizmente, mesmo após cinco anos do envio do anteprojeto, ele ainda aguarda aprovação; a morosidade legislativa, resultado da falta de relevo do assunto nos meios públicos, é ainda um grande óbice aos direitos LGBTIs. Isto 
posto, verifica-se a necessidade de instaurar unidades nas esferas municipais, principalmente, de defesa aos direitos LGBTI e de conscientização da igualdade de gênero.

É imperioso, precipuamente, o estabelecimento de políticas que eliminem a desigualdade do acesso aos serviços de saúde à população LGBTI, como a Política Nacional de Saúde Integral de Lésbicas, Gays, Bissexuais, Travestis e Transexuais (LGBT), que reforça a capacitação dos profissionais do SUS para as necessidades específicas dos grupos, além da elaboração de programas de inclusão destes no mercado de trabalho, visto que a grande discriminação no meio de trabalho faz com que estes indivíduos prefiram por esconder sua vida pessoal. Ainda, observase problema na efetivação de direitos vai além da criação de dispositivos que prevejam a isonomia: o Estado não pode ser o único responsável por normas que garantam efetividade social, e nem o poderia, sendo que uma participação de seus destinatários na fase pré-legislativa colocaria-os em posição de protagonistas e ajudaria o legislador a entender os anseios e as dificuldades de garantir efetividade. É necessário para o direito moderno um cuidado com a fase da criação, aplicação e efeito de suas normas. Uma construção mais sociológica e preocupada com os efeitos práticos da norma, bem como trazer o direito mais próximo da população de forma a garantir uma maior participação em sua criação e um maior interesse.

\section{REFERÊNCIAS}

BARROSO, Luís Roberto. O direito constitucional e a efetividade de suas normas: limites e possibilidades da Constituição Brasileira. - 5.ed - Rio de Janeiro: Renovar, 2001.

BEAUVOIR, Simone. O segundo sexo: fatos e mitos. 4. ed- São Paulo: Difusão europeia de livros, 1970.

BUTLER, Judith. Problemas de gênero: feminismo e subversão da identidade. -8 . ed. - Rio de Janeiro: Ed. Civilização Brasileira.

BORRILLO, Daniel Homofobia: história e crítica de um preconceito. - 1. ed - Belo Horizonte: Autêntica Editora, 2015.

DIAS, Maria Berenice. Homoafetividade e Os Direitos Lgbti - União Homoafetiva - o Preconceito e A Justiça. 6. ed. . Porto Alegre. RT. 2014.

GOMES, Laurentino. 1808. 1. ed., São Paulo: Editora Planeta do Brasil, 2007 
FAVORETO, Selma Regina Dias. A influência da religião no direito. Disponível em:

<http://www.egov.ufsc.br/portal/sites/default/ files/a_influencia_da_religiao_no_direito.pdf > Acesso em: 26 de outubro de 2016.

FOUCAULT, Michel. História da sexualidade I: a vontade de saber. 16. ed. Rio de janeiro. Edições Graal, 1988.

GIDDENS, Anthony. A transformação da intimidade: sexualidade, amor e erotismo nas sociedades modernas -2 . ed. São Paulo: Editora da Universidade Estadual Paulista, 1993.

MELLO, Celso Antônio Bandeira de. Eficácia das normas constitucionais e direitos sociais. - 1. ed. - São Paulo: Malheiros Editores, 2009.

PINTO, Céli Regina Jardim. Feminismo, história e poder. Disponível em: <www.scielo.br/pdf/rsocp/v18n36/03.pdf $>$

Acesso em: 05 de setembro de 2016.

PIOVESAN, Flávia. Direitos humanos e o direito constitucional internacional -4 . ed.São Paulo: MaxLimond, 2000.

RAWLS, John. Uma teoria da justiça - 1. ed - São Paulo: Martins Fontes, 1997
SARLET, Ingo Wolfgang. Dignidade da pessoa humana e direitos fundamentais. Porto Alegre. 4. ed. Livraria do Advogado, 2001.

STF. Ação Direta de Inconstitucionalidade: ADI 4277. Disponível em: <stf.jusbrasil.com.br/jurisprudencia/20627236 lacao-direta-de-inconstitucionalidade-adi4277-df-stf> Acesso em: 02 de novembro de 2016.

STF. Arguição de Descumprimento de Preceito Fundamental: ADPF 132. Disponível em: <www.stf.jus.br/portal/geral/verPdfPaginado. $\underline{\text { asp }}$ id $=433816 \&$ tipo $=$ TP $\&$ descricao $=$ ADPF \%2F132> Acesso em: 02 de novembro de 2016.

UNESCO. Declaração universal sobre a diversidade cultural. Disponível em: $<$ http://unesdoc.unesco.org/images/0012/0012 71/127160por.pdf > Acesso em: 17 de maio de 2016.

CUNHA, Matheus Antonio da. O Artigo 226, $\S^{\circ}$ da Constituição Federal e as uniões homoafetivas. Disponível em: $<$ http://www.ambito juridico.com.br/site/index.php?n_link=revista _artigos_leitura\&artigo_id=9> Acesso em: 22 de março de 2017. 
GOMES, Rodrigo. Mercado de trabalho brasileiro ainda é hostil à população LGBT, indica estudo. Disponível em: <http://www.redebrasilatual.com.br/trabalho/ 2015/05/mercado-de-trabalho-brasileiroainda-e-hostil-a-populacao-lgbt-indicaestudo-170.html> Acesso em: 28 de março de 2017.

RIBEIRO, Djamila. As diversas ondas do feminismo acadêmico. Disponível em: $<$ https://www.cartacapital.com.br/blogs/escrit orio-feminista/feminismo-academico9622.html>. Acesso em: 15 de junho de 2018. Folha de São Paulo. Entenda porque os gays no Brasil sofrem restrição na doação de sangue. Disponível em: < https://www1.folha.uol.com.br/cotidiano/20 $\underline{17 / 11 / 1934835-e n t e n d a-p o r q u e-o s-g a y s-n o-}$ brasil-sofrem-restricao-na-doacao-de-

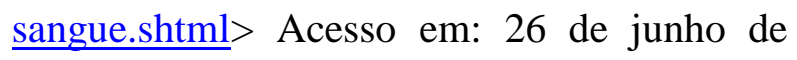
2018.

FERNANDES, Marcella. Representatividade LGBT é mais que aprovar projetos de lei, diz Jean Wyllys. Disponível em: < https://www.huffpostbrasil.com/2018/06/01/r epresentatividade-lgbt-e-mais-que-aprovarprojetos-de-lei-diz-jeanwyllys_a_23447238/>. Acesso em: 23 de junho de 2018. 